\title{
Aberrant expression of CD133 and CD82 in patients with pediatric acute lymphoblastic leukemia and the clinical significance
}

\author{
HONGYAN JI ${ }^{1}$, LI CHEN ${ }^{2}$, YUNPENG DAI ${ }^{1}$, XIAOJUN SUN ${ }^{1}$, XIULI LI ${ }^{1}$, QI WANG ${ }^{1}$, \\ DAOXIN MA ${ }^{3}$, DONGDONG DU ${ }^{1}$, PING ZHAO $^{1}$ and YULIN WANG ${ }^{1}$ \\ ${ }^{1}$ Department of Pediatrics, Shandong Provincial Hospital Affiliated to Shandong University, Jinan, Shandong 250021; \\ ${ }^{2}$ Department of Pediatrics, Anhui Provincial Cancer Hospital, Hefei, Anhui 230000; ${ }^{3}$ Department of Hematology, \\ Qilu Hospital, Shandong University, Jinan, Shandong 250012, P.R. China
}

Received January 12, 2016; Accepted July 11, 2017

DOI: $10.3892 / 01.2017 .6981$

\begin{abstract}
Cluster of differentiation (CD)133 is considered to be a marker of leukemia stem cells (LSCs), which are one of the primary causes of occurrence, drug resistance and relapse of acute lymphoblastic leukemia (ALL). CD82, an adhesion molecule, performs an important role in the interaction between LSCs and their niche. The purpose of the present study was to assess CD133 and CD82 expression in patients with pediatric ALL, and to evaluate the association with the clinical data. Using flow cytometric assessment and reverse transcription-polymerase chain reaction, $\mathrm{CD} 133$ and $\mathrm{CD} 82$ expression levels were measured in the bone marrow (BM) of 37 patients with newly diagnosed (ND) pediatric ALL [ALL-ND; 30 B-cell-ALL (B-ALL) and 7 T-cell-ALL (T-ALL)], in 22 patients with complete remission pediatric ALL (ALL-CR) and in 16 age-matched children without BM disease. BM plasma CD82 concentrations were measured by ELISA. The CD82 mRNA expression level in the patients with ALL-ND was significantly higher compared with that in the controls. CD82 mRNA expression levels in pediatric patients with B cell-ALL (B-ALL) were higher than those in ALL-CR patients and controls. For T-ALL, CD82 expression in ND patients was higher than in controls. CD133 mRNA expression levels in patients with pediatric B-ALL-ND were higher than that of controls and patients with ALL-CR. The frequency of $\mathrm{CD} 34^{+}$cells in pediatric ALL was significantly higher than that in controls. Frequencies of $\mathrm{CD} 34^{+} \mathrm{CD} 133^{+}$or $\mathrm{CD} 34^{+} \mathrm{CD} 82^{+}$cells in pediatric ALL were higher than those in controls. A positive association was observed between CD133 and CD82 mRNA expression in patients with B-ALL. A significant association was observed between CD133 mRNA expression and the hyperdiploid karyotype. Therefore, it was
\end{abstract}

Correspondence to: Dr Ping Zhao, Department of Pediatrics, Shandong Provincial Hospital Affiliated to Shandong University, 324 Jing Wu Road, Jinan, Shandong 250021, P.R. China

E-mail: slyyzp123@163.com

Key words: pediatric, leukemia stem cells, cluster of differentiation 133, cluster of differentiation 82 , clinical data considered that CD133 and CD82 may serve an important role in the evolution of pediatric ALL. CD133 and CD82 should be considered as potential markers for the prognosis of patients with ALL.

\section{Introduction}

Acute lymphoblastic leukemia (ALL) is the most common type of childhood malignancy, and is characterized by uncontrolled clonal proliferation of lymphoid blasts with reduced capacity to differentiate into mature cells (1). The therapeutic outcome for children with newly diagnosed (ND) ALL (ALL-ND) has been markedly improved by risk-adapted treatments and supportive care over the past decades (2). The cure rates have increased to $>80 \%$ in a number of study groups (3-6). However, $15-20 \%$ of patients eventually relapse, which has become the main obstacle to further improve treatment (7). The complexity of the mechanism of ALL progression, together with limited knowledge about the biological features of this disease, presents a challenge to developing novel therapeutic approaches.

Evidence indicates that leukemia stem cells (LSCs), a small population of leukocytes, are responsible for the relapse of ALL $(8,9)$. LSCs have a primitive cell origin and share a number of immunophenotypic characteristics with normal hematopoietic cells (10). LSCs possess the characteristics of self-renewal, proliferation and drug resistance, and have been revealed to express certain LSCs markers, including cluster of differentiation (CD)90, CD96, CD117, CD123 and CD133 (11). CD133, also termed prominin-1, is a five-transmembrane protein, which was originally identified as one marker of hematopoietic stem cells (12). A previous study revealed that CD133 is a more specific marker of hematopoietic stem cells than CD34 (13). The expression of the CD133 antigen in acute leukemia was associated with a more immature phenotype of the blast population and a poor prognosis. However, studies about the expression of CD133 in ALL are conflicting, particularly in pediatric ALL. A number of studies have revealed a high level of CD133 expression in particular cases (14), while others have demonstrated either low level (15) or absent (16) expression.

The regulation of stem cell self-renewal and differentiation requires a specific microenvironment, which is termed 
the stem cell niche (17). Adhesion molecules are known to mediate interactions between hemopoietic cells and the cellular and extracellular stromal microenvironment (18). These interactions are important for maintenance, proliferation, differentiation and homing of hemopoietic progenitors, as well as for LSCs (19). In leukemia, adhesion molecules have been revealed to be differentially expressed and to have an effect on prognosis (20).

The CD82 gene, also termed KAI1, is a member of the tetraspanin superfamily (TM4SF) (21). It is widely accepted that CD82 is associated with cell growth, differentiation and proliferation, T-cell activation, regulation activity and adhesion of natural killer cells. In the context of cancer, CD82 is associated with integrins on the surfaces of various tumor cells, and its expression is associated with metastasis suppression (22). Numerous clinical studies have demonstrated that CD82 is a valid metastasis suppressor gene. Loss of CD82 protein and mRNA was associated with a poor prognosis in a number of solid malignancies, including prostate (23), colon (24), lung (25) and breast (26) cancer. However, there are few studies on the expression level of CD82 in malignant blood disease. Burchert et al (27) reported that CD82 was overexpressed in peripheral blood isolated from patients with acute myeloid leukemia (AML), in leukemic cells from patients with chronic myeloid leukemia (CML) in the accelerated or blastic phase and in chronic lymphocytic leukemia (CLL). It has been suggested that CD82 is abundantly expressed on primitive and hemopoietic progenitor cells (27). Nishioka et al (28) identified that CD82 is aberrantly expressed in CD $34^{+}$CD $38^{-}$acute myelogenous leukemia cells. Subsequently, the study demonstrated that CD82 regulates adhesion and survival of LSCs. However, little is known regarding the expression and roles of CD82 in the bone marrow (BM) of pediatric patients with ALL, and the association between CD82 expression and its clinical characteristics. To date, to the best of our knowledge, no previous study has reported data about the association between CD133 and CD82 expression in pediatric ALL.

In the present study, CD133 and CD82 expression levels were measured in the BM of pediatric patients with ALL, and the association between the expression of CD133 and CD82 was determined, as well as the associations with clinical pathological characteristics.

\section{Patients and methods}

Patients and controls. A total of 59 pediatric patients with ALL (18 females and 41 males; median age, 5 years; age range, 1-13 years) were enrolled in the present study. All patients were diagnosed according to the World Health Organization classification (29). A total of 37 cases were patients with newly diagnosed ALL (ALL-ND), while 22 patients had complete remission ALL (ALL-CR). Among the patients with ALL-ND, 30 patients $(81.08 \%)$ were diagnosed with B-ALL and 7 patients (18.92\%) with T-ALL. BM samples were obtained from ALL-ND patients prior to any treatment. The BM of ALL-CR was aspirated during morphological remission. A total of 16 hematologically normal age-matched BM samples were obtained from patients undergoing a BM aspiration as a part of routine investigation for non-malignant hematological disease (such as idiopathic thrombocytopenia) or lymphoma for staging (proven to be uninvolved on BM biopsy). The karyotype analyses of all patients were performed as part of the routine investigations. Hyperdiploidy karyotype was defined by the presence of 51-68 chromosomes in a karyotype. All patients were treated according to the Chinese Childhood Leukemia Group-Acute Lymphoblastic Leukemia 2008 protocol (30). Enrollment occurred between October 2014 and July 2015 at the Department of Pediatrics, Shandong Provincial Hospital Affiliated to Shandong University (Jinan, China). Written informed consent was obtained from parents on behalf of the children enrolled. The present study was approved by the Medical Ethical Committee of Shandong Provincial Hospital Affiliated to Shandong University.

Reverse transcription-quantitative polymerase chain reaction (RT-qPCR) analysis of CD133 and CD82. Total RNA was obtained from BM mononuclear cells (BMMCs) of patients and healthy controls and isolated using TRIzol (Invitrogen; Thermo Fisher Scientific, Inc., Waltham, MA, USA) in accordance with the manufacturer's protocol. For the reverse transcription reaction, the Prime Script RT reagent kit (Takara Biotechnology, Inc., Dalian, China) was used according to the manufacturer's protocol. Reverse transcription was performed at $37^{\circ} \mathrm{C}$ for $15 \mathrm{~min}$, followed by $85^{\circ} \mathrm{C}$ for $5 \mathrm{sec}$. RT-qPCR was conducted using an ABI Prism 7500 Real-time PCR system (Applied Biosystems; Thermo Fisher Scientific, Inc.), according to the manufacturer's protocol. In the final 10- $\mu 1$ reaction volume, the qPCR contained $5 \mu \mathrm{l} 2 \mathrm{X}$ SYBR-Green Real-time PCR Master mix (Toyobo Biotechnology Co., Ltd., Osaka, Japan), $3.2 \mu \mathrm{l}$ ddH2O, $1 \mu \mathrm{l}$ cDNA sample and $0.4 \mu \mathrm{l}$ forward and reverse primers. All RT-qPCR was conducted on the Roche LightCycler ${ }^{\circledR} 480$ PCR system (Roche Diagnostics, Basel, Switzerland) and performed in triplicate. PCR thermocycling conditions for all genes were as follows: $95^{\circ} \mathrm{C}$ initial activation for $15 \mathrm{~min}$ followed by 45 cycles of $95^{\circ} \mathrm{C}$ for $15 \mathrm{sec}, 60^{\circ} \mathrm{C}$ for $15 \mathrm{sec}$ and $72^{\circ} \mathrm{C}$ for $30 \mathrm{sec}$. The primers were as follows: CD133 forward, 5'-GCATTGGCATCTTCTATG GTT-3' and reverse, 5'-CGCCTTGTCCTTGGTAGTGT-3'; and CD82 forward, 5'-TGTCCTGCAAACCTCCTCCA-3' and reverse, 5'-CCATGAGCATAGTGACTGCCC-3'. The results are expressed relative to the number of $\beta$-actin transcripts, which were used as an internal control. $\beta$-actin was analyzed using the following primers: Forward, 5'-CCTTCCTGGGCA TGGAGTCCTG-3' and reverse, 5'-GGAGCAATGATCTTG ATCTTC-3'. Relative gene expression levels (the amount of target, normalized to endogenous control gene) were calculated using the comparative $\mathrm{Cq}$ method formula, $2^{-\Delta \Delta \mathrm{Cq}}$ (19).

Flow cytometry analysis of CD133- and CD82-expressing cells. BM samples from all patients were collected into EDTA-containing tubes. BMMCs were isolated by Ficoll-Hypaque (GE Healthcare, Chicago, IL, USA) gradient centrifugation at $1,000 \mathrm{x}$ g for $20 \mathrm{~min}$ at $20^{\circ} \mathrm{C}$ and analyzed using three-color flow cytometric analysis. BMMCs $\left(1 \times 10^{6}\right)$ were incubated with $\mathrm{Fc}$ receptor saturation reagent (Beckman Coulter, Inc., Brea, CA, USA) for $20 \mathrm{~min}$ at $20^{\circ} \mathrm{C}$. Subsequently, BMMCs cells were stained with a fluorescein isothiocyanate-conjugated monoclonal antibody (mAb) against CD34 (cat. no. 348053; BD Biosciences, San Jose, CA, USA), a phycoerythrin-conjugated mAb against CD133 (cat. no. 130-098-826; Miltenyi Biotec, 
A

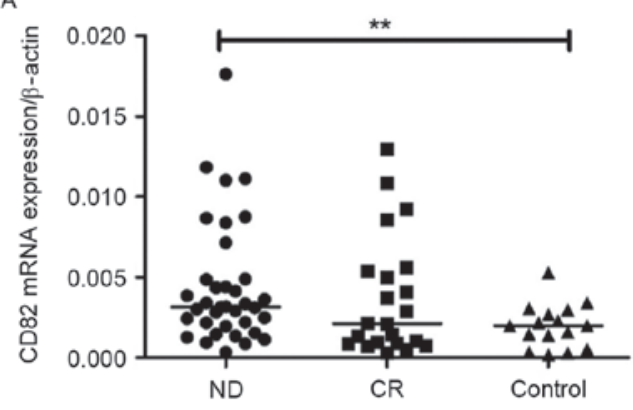

C

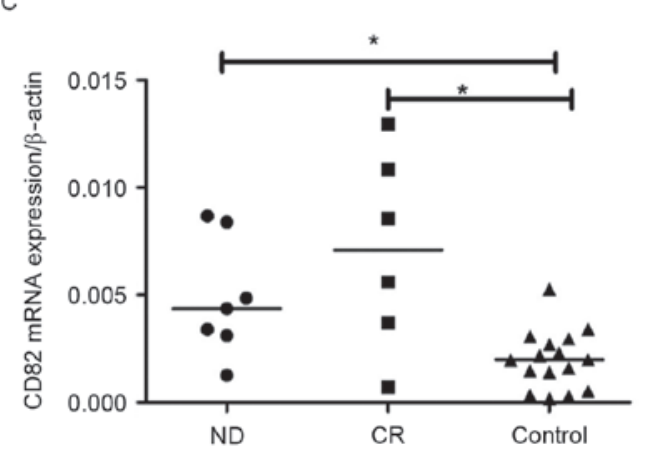

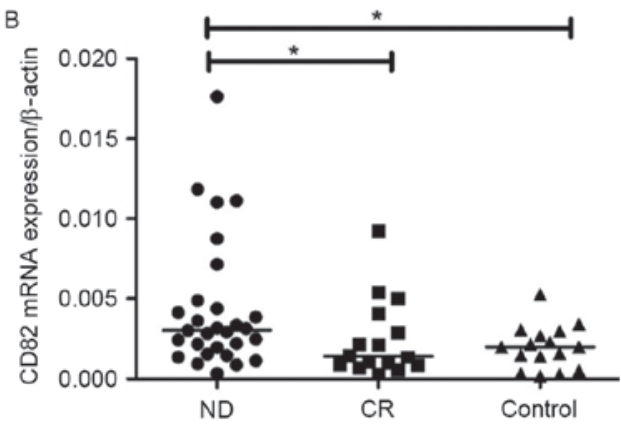

D

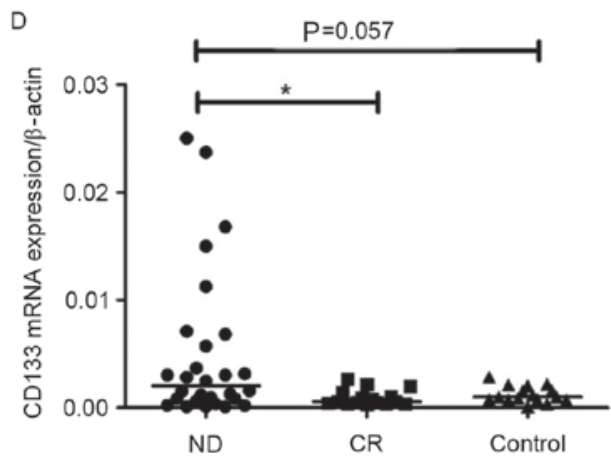

Figure 1. mRNA expression of CD133 and CD82. (A) CD82 mRNA expression in ND was significantly higher than in controls. ** $<0.001$, ND vs. control (B) CD82 mRNA expression in B-ALL ND was significantly higher than in CR and controls. * $\mathrm{P}<0.05$, ND vs. CR or ND vs. control (C) CD82 mRNA expression in T-ALL ND and CR was significantly higher than in controls. ${ }^{*} \mathrm{P}<0.05$, ND vs. control or CR vs. control (D) CD133 mRNA expression was markedly higher in B-ALL ND compared with controls, and CD133 mRNA expression was significantly higher than in CR. *P<0.05, ND vs. CR. ND, newly-diagnosed; CR, complete remission; CD, cluster of differentiation; B-ALL, B cell-acute lymphoblastic leukemia; T-ALL, T cell-acute lymphoblastic leukemia.

Inc., Auburn, CA, USA) and an Alexa Fluor 647-conjugated anti-CD82 antibody (cat. no. 342108; BioLegend, Inc., San Diego, CA, USA), followed by incubation at room temperature in the dark for $20 \mathrm{~min}$. Immunoglobulin $\mathrm{G}(\mathrm{IgG})$ isotype staining was used as a negative control. In all cases, 30,000 events were analyzed. All samples were assayed using a Beckman Gallios Flow Cytometer. Data were analyzed using FlowJo software (version 7.6; Tree Star, Inc., Ashland, OR, USA).

ELISA. BM samples were collected into heparin-anticoagulant vacutainer tubes, including 22 ALL-ND, 16 ALL-CR and 12 control samples. Plasma was obtained by centrifugation at $650 \mathrm{x} \mathrm{g}$ for $5 \mathrm{~min}$ at $20^{\circ} \mathrm{C}$ and stored at $-80^{\circ} \mathrm{C}$ for determination of cytokines. The level of CD82 was detected by a human CD82 ELISA kit (cat. no. CSB-E13037h; Cusabio Biotech Co., Ltd., Wuhan, China), according to the manufacturer's protocol. Serum samples or standard (made according to the manufacturer's protocol) $(100 \mu \mathrm{l})$ were separately added into each well of a 96-well plate and incubated for $2 \mathrm{~h}$ at $37^{\circ} \mathrm{C}$. Biotin antibody (100 $\mu \mathrm{l} ; 1: 100$ dilution) from the ELISA kit was added and incubated for $1 \mathrm{~h}$ at $37^{\circ} \mathrm{C}$. Subsequently, $100 \mu \mathrm{l}$ of horseradish peroxidase-conjugated avidin from the ELISA kit was added and incubated for $1 \mathrm{~h}$ at $37^{\circ} \mathrm{C}$. Tetramethylbenzidine substrate $(90 \mu \mathrm{l})$ was then added and incubated for $15 \mathrm{~min}$ at $37^{\circ} \mathrm{C}$. Finally, $50 \mu \mathrm{l}$ of stop solution was added to each well, and absorbance was read at $450 \mathrm{~nm}$. During the procedure, washing of the plate was according to the ELISA routine method. The lower detection limits were $0.156 \mathrm{ng} / \mathrm{ml}$.

Statistical analysis. Results are expressed as the mean \pm standard deviation, or as the median and range. Student's t-test, $\chi^{2}$ test and Wilcoxon test were performed to assess the differences between two groups. One-way analysis of variance with Tukey's post hoc test was used to assess the difference between three or more groups. Pearson's or Spearman's correlation test was used for correlation analysis depending on data distribution. SPSS software 19.0 (IBM SPSS, Armonk, NY, USA) was used for statistical analysis. $\mathrm{P}<0.05$ was considered to indicate a statistically significant difference.

\section{Results}

Aberrant mRNA expression of CD133 and CD82 in pediatric patients with ALL. CD133 and CD82 mRNA expression levels were determined by RT-qPCR. CD82 mRNA expression level was observably elevated in pediatric patients with ALL-ND (median, 0.0032; range, 0.0003-0.0340) compared with controls (median, 0.0020; range, 0.0002-0.0053) ( $\mathrm{P}=0.0063$ ). However, no significant difference was observed between ND and CR patients (median, 0.0021; range, 0.0003-0.0129) (Fig. 1A). In B-ALL, CD82 mRNA expression in ND patients (median, 0.0031; range, 0.0003-0.0340) was significantly increased compared with CR patients (median, 0.0014; range, 0.0003-0.0092) $(\mathrm{P}=0.0217)$ and controls (median, 0.0022; range, 0.0018-0.0053) ( $\mathrm{P}=0.018)$ (Fig. 1B). In T-ALL, CD82 expression in ND patients (median, 0.0044; range, 0.0012-0.0087) was markedly higher than that in controls (median, 0.0020; range, 0.0002-0.0053) ( $\mathrm{P}=0.0110$; Fig. 1C). No significant difference in CD82 expression was observed between CR (median, 0.0071; range, 0.0007-0.0129) and controls in patients with T-ALL. CD133 mRNA expression in all ND patients (median, 0.0013; range, 0.0001-0.0594) was 
increased compared with that in all $\mathrm{CR}$ patients (median, 0.0008; range, 0.0002-0.0098; $\mathrm{P}=0.012$ ) and controls (median, 0.0010; range, 0.0001-0.0028; $\mathrm{P}=0.007)$. In $\mathrm{B}-\mathrm{ALL}$, the CD133 mRNA expression level was markedly higher in pediatric patients with ALL-ND (median, 0.0027; range, 0.0001-0.0595) compared with controls (median, 0.0010; range, 0.0000-0.0028; $\mathrm{P}=0.0571)$. CD133 mRNA expression in ND patients was also significantly higher than that in $\mathrm{CR}$ patients (median, 0.0005; range, 0.0003-0.0027; P=0.0140; Fig. 1D). In T-ALL, there was no difference between ND (median, 0.0003; range, 0.0001-0.0338) and controls in the mRNA expression of CD133. The difference in CD133 mRNA expression between ND and CR (median, 0.0018; range, 0.0002-0.0098) was not significant $(\mathrm{P}=0.082)$. No significant difference in $\mathrm{CD} 133$ and CD82 mRNA expression was observed between patients with B-ALL and T-ALL. In patients with B-ALL, a positive correlation was observed between CD133 mRNA expression and CD82 mRNA expression in BM $(r=0.3174 ; \mathrm{P}=0.0316$; Fig. 2), however, in patients with T-ALL, the correlation was not significant (data not shown).

Increased CD34-, CD133- and CD82-positive cells in the $B M$ of pediatric ALL. BMMCs of 30 samples (17 ND and 13 control samples) were stained with CD34, CD133 and CD82 antibodies. The typical histogram of CD34 and dot-plot of CD133 and CD82 in pediatric patients with ALL and controls is shown in Fig. 3. In samples from ND patients, the percentage of total $\mathrm{CD} 34^{+}$cells within the BMMC fraction was highly heterogeneous, with a median of $44.67 \%$ (range, $0.50-95.22 \%$ ). Such levels were significantly higher than those observed in controls, in which a median of $6.42 \%$ (range, $1.81-18.52 \%$ ) was observed for total CD34+ cells $(\mathrm{P}<0.01)$ (Fig. 4A). Compared with those in controls (median, $1.41 \%$; range, $0.07-12.89 \%$ ), $\mathrm{CD} 34^{+} \mathrm{CD} 82^{+}$cells in patients with ALL-ND were elevated (median, 39.77\%; range, 0.37-82.74\%; P $<0.01$; Fig. 4B). In the present study, samples were considered positive when $\geq 10 \%$ of cells expressed $\mathrm{CD} 34^{+} \mathrm{CD} 133^{+}$. In patients with ALL-ND, 6 out of $17(35.29 \%)$ patients, the $\mathrm{CD} 34^{+} \mathrm{CD} 133^{+}$frequency was $<10 \%$, but in all the controls the frequency was $>10 \%(\mathrm{P}=0.024$; Fig. 4 C). The difference in $\mathrm{CD} 34^{+} \mathrm{CD} 133^{+}$frequency between ALL and controls was statistically significant $(\mathrm{P}<0.001)$.

BM plasma CD82 level in patients with pediatric ALL. To investigate the expression levels of BM plasma CD82 in patients with pediatric ALL, the levels of CD82 in BM were detected by ELISA. The expression level of plasma CD82 in ND patients $(373.2 \pm 39.7 \mathrm{pg} / \mathrm{ml})$ was significantly higher than that in controls $(249.4 \pm 24.5 \mathrm{pg} / \mathrm{ml})(\mathrm{P}=0.0373)$. The difference

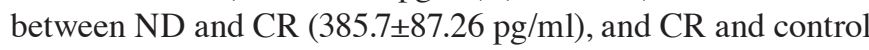
was not statistically significant $(\mathrm{P}>0.05)$.

Positive correlation between percentage of CD133- and CD82-positive cells with $m R N A$ expression. A positive correlation was observed between the frequency of $\mathrm{CD} 34^{+} \mathrm{CD} 82^{+}$cells and CD82 mRNA expression ( $\mathrm{r}=0.549 ; \mathrm{P}=0.022$; Fig. 5A), and between the percentage of $\mathrm{CD} 34^{+} \mathrm{CD} 133^{+}$cells and $\mathrm{CD} 133$ mRNA expression ( $\mathrm{r}=0.617$; $\mathrm{P}=0.008$; Fig. 5B).

Clinical relevance of CD133 and CD82 expression in patients with $A L L$. In the present study, it was demonstrated that

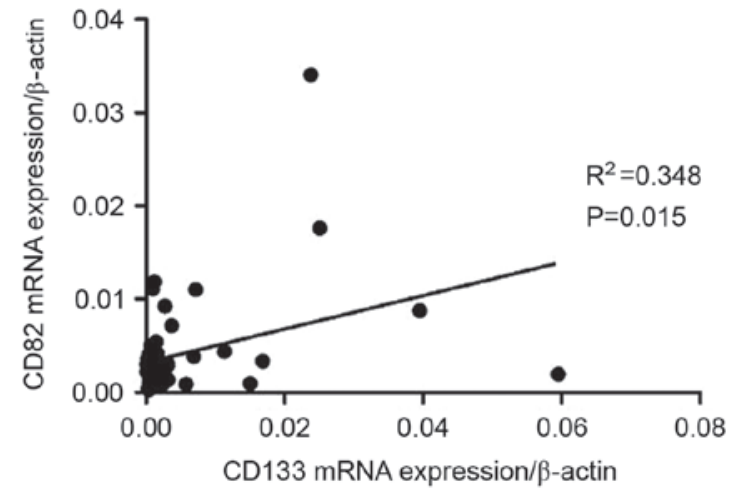

Figure 2. A positive correlation was observed between CD133 and CD82 mRNA expression in pediatric B cell-acute lymphoblastic leukemia. CD, cluster of differentiation.

CD133 mRNA expression in ALL patients with the hyperdiploid karyotype was significantly increased compared with that of those patients with the normal karyotype ( $\mathrm{P}=0.003$; Fig. 6). The expression of CD133 and CD82 exhibited no association with other clinical factors, including sex, age, white blood cells, infusion genes and the risk stage, in patients with ALL (Table I).

\section{Discussion}

It has been well accepted that LSCs, which possess the characteristics of self-renewal, proliferation and drug resistance, perform an important role in leukemia progression $(31,32)$. LSCs are responsible for the relapse of acute leukemia. CD34 has been used to distinguish between immature and mature cells (33). In the present study, it was demonstrated that in patients with ALL-ND, the percentage of total CD34 ${ }^{+}$cells within the BMMC fraction was significantly higher than that observed in the controls, which was consistent with previous studies $(15,34,35)$.

Previous studies demonstrated that LSCs express CD133. CD133 has been used for cancer stem cell identification in several types of cancer, including glioblastoma (36), melanoma (37), liver cancer (38), osteosarcoma (39) and colon cancer (40). There are numerous studies on the expression of CD133 in acute leukemia, however, a few studies on the expression of CD133 in ALL, particularly in pediatric ALL, are contradictory. The expression of CD133 antigen in acute leukemia was associated with a more immature phenotype of the blast population and a bad prognosis. Mak et al suggested that pro-B-ALL cell samples with 11q23-anomalies and mixed lineage leukemia (MLL) gene translocations were positive for CD133 (41). The expression of 11q23-anomalies and MLL were high-risk factors in pediatric ALL. Crucially, it was demonstrated that $\mathrm{CD}_{133}{ }^{+}$cells were more resistant to treatment with the key components in pediatric ALL therapy, such as dexamethasone and vincristine, than the bulk leukemia population. Therefore, the poor clinical outcomes associated with positive CD133 expression in ALL cases could be explained by evidence that $\mathrm{CD} 133^{+}$cells show high resistance to chemotherapy. Furthermore, high resistance to chemotherapy is attributed to evidence that there is increased expression of the multidrug resistance genes and DNA mismatch repair genes, as well as 

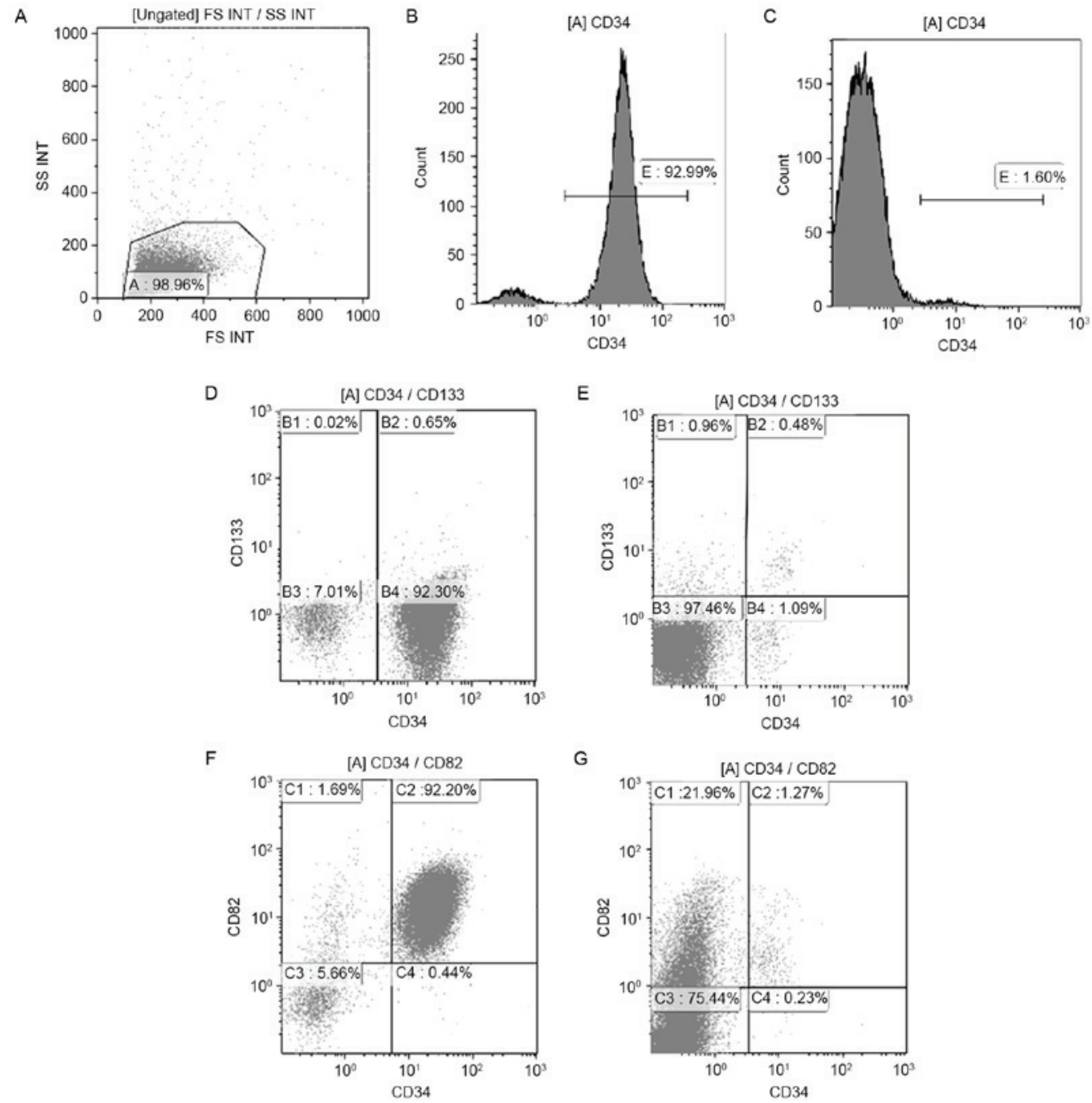

Figure 3. Histogram of CD34+ cells and dot-plots of $\mathrm{CD} 34^{+} \mathrm{CD} 133^{+}$and $\mathrm{CD} 34^{+} \mathrm{CD} 82^{+}$cells in patients with ALL-ND and controls. (A) Lymphocytes were gated in A. Histogram of CD34+ cells in (B) patients with ALL-ND and (C) healthy controls. Typical dot-plot of CD34 ${ }^{+}$CD133 ${ }^{+}$cells in (D) patients with ALL-ND and (E) healthy controls. Typical dot-plot of CD34 ${ }^{+} \mathrm{CD} 82^{+}$cells in (F) patients with ALL-ND and (G) healthy controls. CD, cluster of differentiation; ALL-ND, newly-diagnosed acute lymphoblastic leukemia; SS INT, side scatter; FS INT, forward scatter.

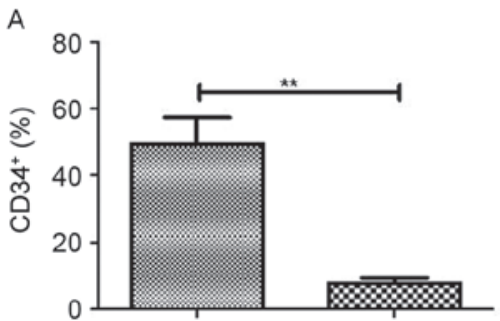

ALL-ND

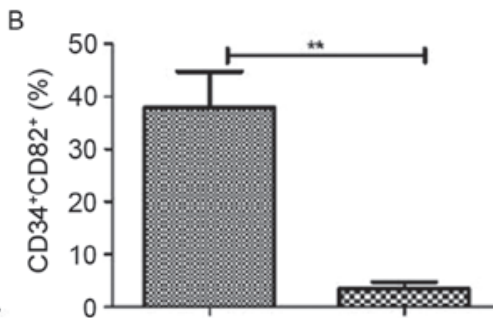

ALL-ND

Control

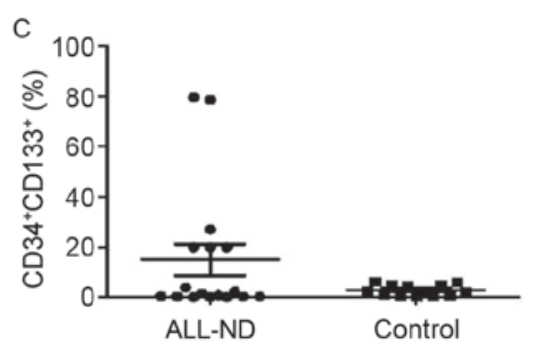

Figure 4. Frequency of $\mathrm{CD} 34^{+}, \mathrm{CD} 34^{+} \mathrm{CD} 82^{+}$and $\mathrm{CD} 34^{+} \mathrm{CD} 133^{+}$cells in patients with ALL-ND and controls. (A) Frequency of CD34-positive cells in patients with ALL-ND was significantly increased compared with controls. (B) Frequency of CD $34^{+} \mathrm{CD} 82^{+}$cells in patients with ALL-ND was significantly higher than in controls. (C) In 6 of 17 patients with ALL-ND, the frequency of CD $34^{+} \mathrm{CD} 133^{+}$cells was $>10 \%$, whereas no control patients exhibited a frequency of $\mathrm{CD}^{2} 4^{+} \mathrm{CD} 133^{+}$cells of $10 \%$. CD, cluster of differentiation; ALL-ND, newly diagnosed acute lymphoblastic leukemia. ${ }^{* *} \mathrm{P}<0.001$ vs. controls.

genes that inhibit apoptosis in the CD133-expressing LSCs. In addition, it was demonstrated that the associations between expression of cancer stem cell specificity are maintained by tight regulation of CD133 expression at transcriptional and post-translational levels (42). Therefore, evaluating the expression level of CD133 is important in clinical diagnosis and treatment.
The CD133 expression level of BM was measured in pediatric patients with ALL-ND, patients with ALL-CR and a control group in the present study. The results demonstrated that CD133 expression in pediatric ALL-ND was significantly increased compared with that in the controls, and notably, that it decreased when patients achieved CR. Regarding correlations between CD133 expression and a number of the studied 
Table I. Associations between CD133 and CD82 mRNA expression and clinicopathological characteristics of pediatric patients with newly-diagnosed acute lymphoblastic leukemia.

\begin{tabular}{|c|c|c|c|c|c|}
\hline \multirow[b]{2}{*}{ Characteristic } & \multirow[b]{2}{*}{ Patients, $\mathrm{n}$} & \multicolumn{2}{|c|}{ CD133 mRNA } & \multicolumn{2}{|c|}{ CD82 mRNA } \\
\hline & & Relative expression ${ }^{\mathrm{a}}$ & P-value & Relative expression ${ }^{\mathrm{a}}$ & $\mathrm{P}$-value \\
\hline Sex & & & 0.1676 & & 0.2850 \\
\hline Male & 24 & $0.0052 \pm 0.0019$ & & $0.0060 \pm 0.0015$ & \\
\hline Female & 13 & $0.0115 \pm 0.0049$ & & $0.0038 \pm 0.0006$ & \\
\hline Age & & & 0.2752 & & 0.7855 \\
\hline $1-10$ years & 33 & $0.0083 \pm 0.0024$ & & $0.0051 \pm 0.0011$ & \\
\hline$<1$ or $>10$ years & 4 & $0.0006 \pm 0.0002$ & & $0.0060 \pm 0.0023$ & \\
\hline WBCs, $\times 10^{9}$ & & & 0.0769 & & 0.6873 \\
\hline$<10$ & 14 & $0.0116 \pm 0.0044$ & & $0.0065 \pm 0.0024$ & \\
\hline $10-50$ & 13 & $0.0024 \pm 0.0007$ & & $0.0045 \pm 0.0010$ & \\
\hline$>50$ & 4 & $0.0006 \pm 0.002$ & & $0.0041 \pm 0.0016$ & \\
\hline Risk stage & & & 0.5818 & & 0.9045 \\
\hline High & 5 & $0.0131 \pm 0.0116$ & & $0.0045 \pm 0.0012$ & \\
\hline Middle & 28 & $0.0064 \pm 0.0019$ & & $0.0052 \pm 0.0012$ & \\
\hline Stander & 4 & $0.0078 \pm 0.0058$ & & $0.0064 \pm 0.0037$ & \\
\hline Karyotype & & & 0.0341 & & 0.2720 \\
\hline Hyperdiploid & 11 & $0.0020 \pm 0.0007$ & & $0.0040 \pm 0.0011$ & \\
\hline Normal & 14 & $0.0104 \pm 0.00132$ & & $0.0073 \pm 0.0024$ & \\
\hline
\end{tabular}

${ }^{a}$ Data presented as mean \pm standard deviation. CD, cluster of differentiation; WBC, white blood cell.
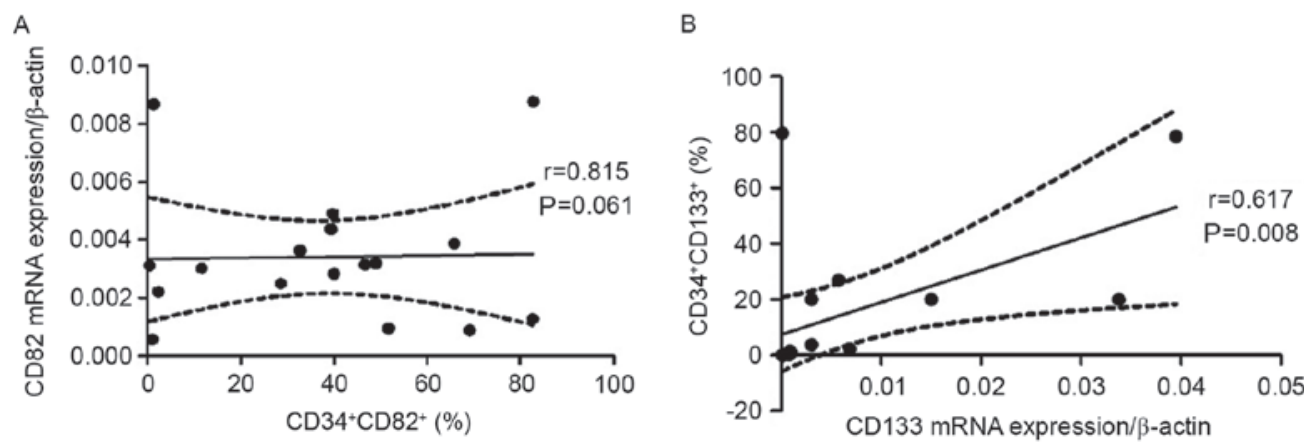

Figure 5. Relevance between $\mathrm{CD} 34^{+} \mathrm{CD} 133^{+}$and $\mathrm{CD} 34^{+} \mathrm{CD} 82^{+}$cell frequency and $\mathrm{CD} 133$ and $\mathrm{CD} 82 \mathrm{mRNA}$ expression in pediatric patients with acute lymphoblastic leukemia. (A) A positive correlation was observed between the percentage of CD34 ${ }^{+} \mathrm{CD} 82^{+}$cells and CD82 mRNA expression. (B) A positive correlation was observed between the percentage of $\mathrm{CD} 34^{+} \mathrm{CD} 133^{+}$cells and $\mathrm{CD} 133 \mathrm{mRNA}$ expression. $\mathrm{CD}$, cluster of differentiation.

standard prognostic factors, a highly significant association between CD133 mRNA expression and the hyperdiploid karyotype was demonstrated. The CD133 mRNA expression level was increased in patients with the hyperdiploid karyotype compared with that in patients with the normal chromosome karyotype. In addition, a patient who presented with the MLL/ALL-1-fused gene on chromosome 4 (AF4) mutation expressed a higher CD133 mRNA level compared with other patients. This observation was consistent with the hypothesis by Mak et al which stated that MLL fusion-associated gene AF4 promotes CD133 transcription (41).

Originally identified as a tumor metastasis suppressor in prostate carcinoma (37), the CD82 gene is a member of the TM4SF that is located on human chromosome 11p11.2. CD82

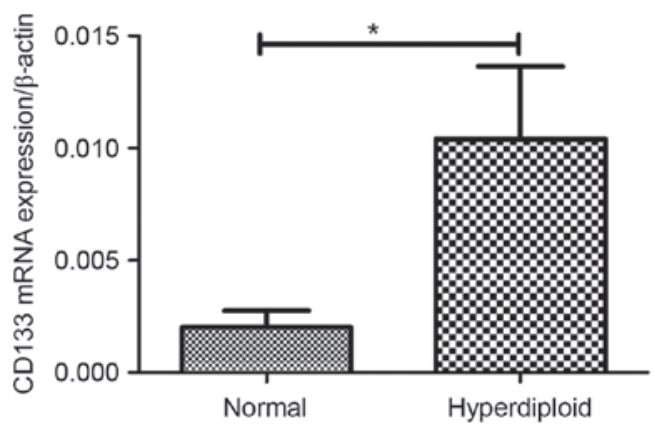

Figure 6. Association between CD133 mRNA expression and karyotype. CD133 mRNA expression in patients with acute lymphoblastic leukemia with hyperdiploid karyotype was significantly increased compared with normal karyotype. CD, cluster of differentiation. * $\mathrm{P}<0.05$ Normal vs. hyperdiploid. 
performs an important function in cell fusion, migration, adhesion, signaling, fertilization, differentiation and invasion. A previous study demonstrated that CD82 gene expression is under-regulated in the majority of metastatic cancer types, which was in contrast to CD82 expression in malignant hematological disease. It had been revealed that CD82 was overexpressed in patients with CML in the accelerated or blastic phase, as well as in patients with AML and CLL. Nishioka et al (43) detected aberrant expression of CD82 in $\mathrm{CD} 34^{+} \mathrm{CD} 38^{-} \mathrm{AML}$ cells. Importantly, it was revealed that downregulation of $\mathrm{CD} 82$ in $\mathrm{CD} 34^{+} \mathrm{CD} 38^{-} \mathrm{AML}$ cells could inhibit the adhesion and colony forming ability of these cells. In addition, in $\mathrm{CD}^{2} 4^{+} / \mathrm{CD} 38^{-}$AML cells, CD82 downregulation significantly impaired engraftment of the cells in severely immunocompromised mice. Taken together, the results suggested that aberrant CD82 expression may serve a role in the adhesion of LSCs to the BM microenvironment and in LSC survival (28). Subsequently, Nishioka et al (43) demonstrated that the CD82/signal transducer and activator of transcription 5/interleukin-10 signaling pathway is involved in the survival of $\mathrm{CD}^{2} 4^{+} / \mathrm{CD} 38^{-}$AML cells, while Nishioka et al (44) demonstrated the same for the p38-mitogen-activated protein kinase signaling pathway. Therefore, CD82 performs an important role in leukemogenesis. The aforementioned studies were all performed in AML cell lines, and to the best of our knowledge, no data has been reported about the expression level and role of CD82 BM in pediatric patients with ALL. In the present study, the expression level of CD82 in the BM of pediatric ALL patients was evaluated. It was demonstrated that CD82 expression in the BM of all pediatric patients with ALL-ND increased compared with that in the controls. In B-ALL, CD82 expression in ND patients was significantly higher than that in the CR patients and controls at the mRNA and protein levels. The level of CD82 in BM plasma in patients with ND B-ALL was also higher than that in controls, which was consistent with the RT-qPCR and flow cytometry results. The results were consistent with those of patients with AML and CML. This may indicate that CD82 is also involved in the development of ALL progression in pediatrics. The mechanism of the role of CD82 in ALL development requires additional study in the future.

In conclusion, the present study revealed that CD133 and CD82 were aberrantly expressed in pediatric patients with ALL. In addition, a significant positive correlation existed between CD133 and CD82 expression in the BM. Furthermore, there was a significant correlation between CD133 mRNA expression and a hyperdiploid karyotype. Taken together, the results of the present study indicated that CD133 and CD82 may represent important potential immunotherapeutic targets in pediatric ALL. Although the precise molecular mechanism involved in this process is unclear, the results have potential clinical benefits. CD133 and CD82 expression, which could be detected by fluorescence-activated cell sorting, may be a useful molecular marker to evaluate disease progress in patients with ALL. The combined detection of CD133 and CD82 can reflect the biological behavior of ALL, to a certain extent, and may be used for molecular targeting therapy. However, the number of samples in the present study was relatively small. Additional larger prospective studies are required to verify the present observations.

\section{Acknowledgements}

The present study was supported by grants from the National Natural Science Foundation of Shandong Province (grant no. ZR2015PH060) and the Outstanding Young Scientist Research Award Foundation of Shandong Province (grant no. BS2010YY004).

\section{References}

1. Pui CH, Robison LL and Look AT: Acute lymphoblastic leukaemia. Lancet 371: 1030-1043, 2008.

2. Pui CH, Carroll WL, Meshinchi S and Arceci RJ: Biology, risk stratification, and therapy of pediatric acute leukemias: An update. J Clin Oncol 29: 551-565, 2011.

3. Möricke A, Zimmermann M, Reiter A, Henze G, Schrauder A, Gadner H, Ludwig WD, Ritter J, Harbott J, Mann G, et al: Long-term results of five consecutive trials in childhood acute lymphoblastic leukemia performed by the ALL-BFM study group from 1981 to 2000 . Leukemia 24: 265-284, 2010.

4. Hunger SP, Lu X, Devidas M, Camitta BM, Gaynon PS, Winick NJ, Reaman GH and Carroll WL: Improved survival for children and adolescents with acute lymphoblastic leukemia between 1990 and 2005: A report from the children's oncology group. J Clin Oncol 30: 1663-1669, 2012.

5. Conter V, Aricò M, Basso G, Biondi A, Barisone E, Messina C, Parasole R, De Rossi G, Locatelli F, Pession A, et al: Long-term results of the Italian Association of Pediatric Hematology and Oncology (AIEOP) Studies 82, 87, 88, 91 and 95 for childhood acute lymphoblastic leukemia. Leukemia 24: 255-264, 2010.

6. Pui CH, Campana D, Pei D, Bowman WP, Sandlund JT, Kaste SC, Ribeiro RC, Rubnitz JE, Raimondi SC, Onciu M, et al: Treating childhood acute lymphoblastic leukemia without cranial irradiation. N Engl J Med 360: 2730-2741, 2009.

7. Bhojwani D and Pui CH: Relapsed childhood acute lymphoblastic leukaemia. Lancet Oncol 14: e205-e217, 2013.

8. Styczynski J and Drewa T: Leukemic stem cells: From metabolic pathways and signaling to a new concept of drug resistance targeting. Acta Biochim Pol 54: 717-726, 2007.

9. O'Brien CA, Pollett A, Gallinger S and Dick JE: A human colon cancer cell capable of initiating tumour growth in immunodeficient mice. Nature 445: 106-110, 2007.

10. Makino S: The role of tumor stem-cells in regrowth of the tumor following drastic applications. Acta Unio Int Contra Cancrum 15 (Suppl 1): S196-S198, 1959.

11. Chávez-González A, Dorantes-Acosta E, Moreno-Lorenzana D, Alvarado-Moreno A, Arriaga-Pizano L and Mayani H: Expression of CD90, CD96, CD117, and CD123 on different hematopoietic cell populations from pediatric patients with acute myeloid leukemia. Arch Med Res 45: 343-350, 2014

12. Hong D, Gupta R, Ancliff P, Atzberger A, Brown J, Soneji S, Green J, Colman S, Piacibello W, Buckle V, et al: Initiating and cancer-propagating cells in TEL-AML1-associated childhood leukemia. Science 319: 336-339, 2008.

13. Toren A, Bielorai B, Jacob-Hirsch J, Fisher T, Kreiser D, Moran O, Zeligson S, Givol D, Yitzhaky A, Itskovitz-Eldor J, et al: CD133-positive hematopoietic stem cell 'stemness' genes contain many genes mutated or abnormally expressed in leukemia. Stem cells 23: 1142-1153, 2005.

14. Wuchter C, Ratei R, Spahn G, Schoch C, Harbott J, Schnittger S, Haferlach T, Creutzig U, Sperling C, Karawajew Land Ludwig WD: Impact of CD133 (AC133) and CD90 expression analysis for acute leukemia immunophenotyping. Haematologica 86: 154-161, 2001.

15. Miraglia S, Godfrey W, Yin AH, Atkins K, Warnke R, Holden JT, Bray RA, Waller EK and Buck DW: A novel five-transmembrane hematopoietic stem cell antigen: Isolation, characterization, and molecular cloning. Blood 90: 5013-5021, 1997.

16. Horn PA, Tesch H, Staib P, Kube D, Diehl V and Voliotis D: Expression of AC133, a novel hematopoietic precursor antigen, on acute myeloid leukemia cells. Blood 93: 1435-1437, 1999.

17. Morrison SJ and Scadden DT: The bone marrow niche for haematopoietic stem cells. Nature 505: 327-334, 2014.

18. Sheppard D: In vivo functions of integrins: Lessons from null mutations in mice. Matrix Biol 19: 203-209, 2000.

19. Möhle R, Murea S, Kirsch M and Haas R: Differential expression of L-selectin, VLA-4, and LFA-1 on CD34+ progenitor cells from bone marrow and peripheral blood during G-CSF-enhanced recovery. Exp Hematol 23: 1535-1542, 1995. 
20. Baer MR, Stewart CC, Lawrence D, Arthur DC, Byrd JC, Davey FR, Schiffer CA and Bloomfield CD: Expression of the neural cell adhesion molecule CD56 is associated with short remission duration and survival in acute myeloid leukemia with $\mathrm{t}(8 ; 21)(\mathrm{q} 22 ; \mathrm{q} 22)$. Blood 90: 1643-1648, 1997.

21. Gil ML, Vita N, Lebel-Binay S, Miloux B, Chalon P, Kaghad M, Marchiol-Fournigault $\mathrm{C}$, Conjeaud $\mathrm{H}$, Caput $\mathrm{D}$, Ferrara $\mathrm{P}$, et al: A member of the tetra spans transmembrane protein superfamily is recognized by a monoclonal antibody raised against an HLA class I-deficient, lymphokine-activated killer-susceptible, B lymphocyte line. Cloning and preliminary functional studies. J Immunol 148: 2826-2833, 1992.

22. Miranti CK: Controlling cell surface dynamics and signaling: How CD82/KAI1 suppresses metastasis. Cell Signal 21: 196-211, 2009.

23. Liu W, Iiizumi-Gairani M, Okuda H, Kobayashi A, Watabe M, Pai SK, Pandey PR, Xing F, Fukuda K, Modur V, et al: KAI1 gene is engaged in NDRG1 gene-mediated metastasis suppression through the ATF3-NFkappaB complex in human prostate cancer. J Biol Chem 286: 18949-18959, 2011.

24. Wu DH, Liu L, Chen LH and Ding YQ: KAI1 gene expression in colonic carcinoma and its clinical significances. World J Gastroenterol 10: 2245-2249, 2004.

25. Goncharuk VN, del-Rosario A, Kren L, Anwar S, Sheehan CE, Carlson JA and Ross JS: Co-downregulation of PTEN, KAI-1, and $\mathrm{nm} 23-\mathrm{H} 1$ tumor/metastasis suppressor proteins in non-small cell lung cancer. Ann Diagn Pathol 8: 6-16, 2004.

26. Mooez S, Malik FA, Kayani MA, Rashid R, Zahid A and Khan A Expressional alterations and transcript isoforms of metastasis suppressor genes (KAI1 and KiSS1) in breast cancer patients. Asian Pac J Cancer Prev 12: 2785-2791, 2011.

27. Burchert A, Notter M, Dietrich Menssen H, Schwartz S, Knauf W, Neubauer A and Thiel E: CD82 (KAI1), a member of the tetraspan family, is expressed on early haemopoietic progenitor cells and up-regulated in distinct human leukaemias. Br J Haematol 107 494-504, 1999.

28. Nishioka C, Ikezoe T, Furihata M, Yang J, Serada S, Naka T, Nobumoto A, Kataoka S, Tsuda M, Udaka K and Yokoyama A: CD34 ${ }^{+} / \mathrm{CD} 38^{-}$acute myelogenous leukemia cells aberrantly express CD82 which regulates adhesion and survival of leukemia stem cells. Int J Cancer 132: 2006-2019, 2013.

29. Vardiman JW: The World Health Organization (WHO) classification of tumors of the hematopoietic and lymphoid tissues: An overview with emphasis on the myeloid neoplasms. Chem Biol Interact 184: 16-20, 2010

30. Liu X, Zou Y, Wang H, Chen X, Ruan M, Chen Y, Yang W, Guo Y, Liu T, Zhang L, et al: Treatment outcome of childhood standard-risk and median-risk acute lymphoblastic leukemia with CCLG-2008 protocol. Zhonghua Er Ke Za Zhi 52: 449-454, 2014 (In Chinese).

31. Jordan CT, Guzman ML and Noble M: Cancer stem cells. N Engl J Med 355: 1253-1261, 2006.
32. Dick JE: Stem cell concepts renew cancer research. Blood 112 4793-4807, 2008

33. Guenova M and Balatzenko G: CD133-2 (AC141) expression analysis in acute leukemia immunophenotyping in correlation to CD34 and P-glycoprotein. Hematology 13: 137-141, 2008.

34. Bene MC, Castoldi G, Knapp W, Ludwig WD, Matutes E, Orfao A and van't Veer MB: Proposals for the immunological classification of acute leukemias. European Group for the Immunological Characterization of Leukemias (EGIL). Leukemia 9: 1783-1786, 1995.

35. Gallacher L, Murdoch B, Wu DM, Karanu FN, Keeney M and Bhatia M: Isolation and characterization of human CD34(-)Lin(-) and CD34(+)Lin(-) hematopoietic stem cells using cell surface markers AC133 and CD7. Blood 95: 2813-2820, 2000.

36. Yamamuro S, Okamoto Y, Sano E, Ochiai Y, Ogino A, Ohta T, Hara H, Ueda T, Nakayama T, Yoshino A and Katayama Y: Characterization of glioma stem-like cells from human glioblastomas. Int J Oncol 47: 91-96, 2015.

37. Welte Y, Davies C, Schäfer R and Regenbrecht CR: Patient derived cell culture and isolation of $\mathrm{CD} 133^{+}$putative cancer stem cells from melanoma. J Vis Exp: e50200, 2013.

38. Bahnassy AA, Fawzy M, El-Wakil M, Zekri AR, Abdel-Sayed A and Sheta M: Aberrant expression of cancer stem cell markers (CD44, CD90 and CD133) contributes to disease progression and reduced survival in hepatoblastoma patients: 4-year survival data. Transl Res 165: 396-406, 2015.

39. Li J, Zhong XY, Li ZY, Cai JF, Zou L, Li JM, Yang T and Liu W: CD133 expression in osteosarcoma and derivation of CD133 ${ }^{+}$cells. Mol Med Rep 7: 577-584, 2013.

40. Wang C, Xie J, Guo J, Manning HC, Gore JC and Guo N: Evaluation of CD44 and CD133 as cancer stem cell markers for colorectal cancer. Oncol Rep 28: 1301-1308, 2012.

41. Mak AB, Nixon AM and Moffat J: The mixed lineage leukemia (MLL) fusion-associated gene AF4 promotes CD133 transcription. Cancer Res 72: 1929-1934, 2012.

42. Pellacani D, Packer RJ, Frame FM, Oldridge EE, Berry PA, Labarthe MC, Stower MJ, Simms MS, Collins AT and Maitland NJ: Regulation of the stem cell marker CD133 is independent of promoter hypermethylation in human epithelial differentiation and cancer. Mol Cancer 10: 94, 2011.

43. Nishioka C, Ikezoe T, Yang J, Nobumoto A, Kataoka S, Tsuda M, Udaka K and Yokoyama A: CD82 regulates STAT5/IL-10 and supports survival of acute myelogenous leukemia cells. Int J Cancer 134: 55-64, 2014.

44. Nishioka C, Ikezoe T, Yang J and Yokoyama A: Tetraspanin family member, CD82, regulates expression of EZH2 via inactivation of p38 MAPK signaling in leukemia cells. PLoS One 10: e0125017, 2015. 